\title{
Effect of blender and blending time on color and aroma characteristics of juice and its freeze-dried powder of Pandanus amaryllifolius Roxb. leaves (pandan)
}

\begin{abstract}
The color and aroma properties of Pandanus amaryllifolius Roxb. leaves (pandan) were studied by mechanical extraction using normal and turbo blade blenders under different blending times (60ï $180 \mathrm{~s}$ ). The extracted juice was freeze-dried into powders and its aroma components were measured in a solid-phase microextraction using gas chromatography/mass spectrometry (SPME-GC/MS) analysis. The turbo blade blender provided maximum color pigment of greenness and yellowness at blending time of $90 \mathrm{~s}$ as compared to the normal blender that required $180 \mathrm{~s}$. In GC-MS analysis, the major component, 2-acetyl-1-pyrroline, was found to be one time higher in the freeze-dried pandan juice samples obtained from turbo blade blender than normal blender. Other components including the cis-3-hexanal, 2methylene-4-pentenenitrile and 1,2,4-trimethylbenzene were also detected in the samples. In conclusion, the turbo blade blender is more effective than normal laboratory blender in terms of color extraction, particle size reduction and the aroma retention.
\end{abstract}

Keyword: Blender; Color; Pandan; Pandanus amaryllifolius; Turbo blender 